\title{
SPIRACHE, TEXT UND TEXTSORTEN: ZUR PROBLEMATIK VON TEXTTYPOLOGIE
}

Textlinguistik und Texttheorie tun sich offenbar schwer damit, Grundsätzliches eindeutig zu definieren und auf diese Weise festzulegen. Was ich damit meine, ist die Tatsache, daß wir zwischen einer geradezu beliebigen Anzahl von Definitionen wählen können, wenn es um den zentralen Begriff 'Text' geht, abhängig nur von den isoliert bzw. kombinatorisch angewandten spezifischen textinternen oder textexternen Parametern, obwohl eine definitive 'Text'-Definition Basis aller Reflektionen über linguistische Textsorten und Texttypologien sein sollte. Sicher beruht die Schwierigkeit einer 'Text'-Definition unmittelbar auf der Schwierigkeit, das Phänomen 'Sprache' - per se als differentia specifica des Menschen und als einzelsprachliche Konkretisierung dieser differentia specifica- auf einen definitorischen Nenner zu bringen, weil die Komplexität dieses Phänomens 'Sprache' und die sinnlich-irrationalen Valenzen dieses geistigseelischen Intentionalitäts-Vehikels unseres Bewußtseins (im Sinne Edmund Husserls) unsere theoretisch-rationalen Festlegungsbemühungen immer wieder vereiteln, woraus Ludwig Wittgenstein die logische Konsequenz zog, neben die historisch gewachsene und 'verwachsene' 'Umgangssprache' eine schlicht-exakte philosophische 'Idealsprache' setzen zu wollen.

Da das sprachphilosophische Phänomen 'Sprache' also, in seiner erwähnten doppelten Bedeutung, die linguistischen termini technici 'Text' und 'Textsorte' mit beinhaltet, ihnen logisch zugeordnet und übergeordnet ist, möchte ich, wie im Titel meines Beitrages angedeutet, meine Überlegungen zur Problematik von Texttypologien bei den Begriffen 'Sprache' und 'Text' ansetzen.

Im Hinblick auf ihre irrational-sinnlichen Substrukturen ist es vielleicht nicht weiter erstaunlich, daß die 'Sprache' in der modernen Bewußtseinsphilosophie, von René Descartes bis zu Georg Wilhelm Friedrich Hegel, durchaus vernachlässigt wurde, wofür etwa Immanuel Kants epochale "Kritik der reinen Vernunft" (1781) beredetes Zeugnis ablegt. Erstaunlich ist, daß bereits Platon, der dem Phänomen 'Sprache' einen eigenen Dialog "Kratylos" widmete, der Sprache und ihren Worten als kognitives Vehikel und Medium - wohl aus den gleichen logischen Gründen wie Ludwig Wittgenstein - mißtraute: "Auf welche Weise man nun Erkenntnis der Dinge erlernen oder selbst finden soll, das einzusehen, sind wir vielleicht nicht genug, ich und du; es genüge uns aber schon, darin übereinzukommen, daß nicht durch die Worte, sondern weit lieber 
durch sie selbst man sie (die Dinge) erforschen und kennenlernen muß als durch die Worte." ${ }^{1}$ Es blieb dem philosophischen Geisteswissenschaftler, Theologen und Literaten Johann Gottfried Herder vorbehalten, 1770/72 in seiner "Abhandlung über den Ursprung der Sprache" Sprache per se als eine distinktiv-intelligente, besonnen-theoretisch strukturierte spezifische Fähigkeit des menschlichen Bewußtseins zu definieren, die es dem Menschen erlaubt, sinnliche Reize und emotionale Affekte nicht handlungsaktiv zu extrovertieren, sondern kognitiv zu introvertieren, in Sprache umzusetzen und sich ihrer als Sprache zu entäußern. Für Herder ist Sprache 'Ausdruck' der 'WahrNehmung' und der disjunktiven 'Unter-Scheidung' eines neuen Erlebnisses, und Sprache ist zugleich Fixierung dieses neuen kognitiven Erlebnisses, um so das Neu-Erfahrene permanent als konnotative Distinktion zu speichern, zu 'bannen'. Damit verleihen die Wort-Komponenten der Sprache, gewissermaßen als Zeichen-Symbole, den ständig wechselnden Bewußtseinsinhalten Dauer. ${ }^{2}$ Auf Herders anthropologischen Sprachvorstellungen aufbauend, entwickelte reichlich 60 Jahre später Wilhelm von Humboldt seine Sprach-Konzeption unter dem indikativen Titel "Über die Verschiedenheit des menschlichen Sprachbaues und ihren Einfluß auf die geistige Entwicklung des Menschengeschlechtes" $(1836),{ }^{3}$ deren Grundideen sich noch - mutatis mutandis - in der "Inhaltsbezogenen Grammatik" Leo Weisgerbers und in der generativen Transformationsgrammatik Noam Chomsky's finden lassen. Wie Herder betont Humboldt die Relevanz der Sprache für das menschliche Selbstverständnis; sie ist ihm tiefster Ausdruck menschlicher Natur, mithin als "energeia" eine dynamisch-spontane Kraft: "Man muß die Sprache nicht sowohl wie ein todtes Erzeugtes, sondern weit mehr wie eine Erzeugung ansehen..." ${ }^{4}$ Wenn Humboldt ferner sagt, "daß er (der Mensch) nichts aus sich hinauszusetzen vermag, das nicht augenblicklich zu einer auf ihn zurückwirkenden und sein ferneres Schaffen bedingenden Masse wird...", dann ist diese Feststellung für den Staatsmann und Philosophen Humboldt das Grundgesetz menschlichen Daseins, ein dialektisches Prinzip von Wirkung und Rückwirkung, von Spontaneität und Rezep-

1 Platon, Kratylos. In: Sämtliche Werke 2. Hg. von W.F.Otto/E.Grassi/G.Plamböck. Hamburg (Rowohlts Klassiker 14) 1957, S.180 (439b) - Diese kritische Einsicht Platons klingt wie ein kontrapunktisches Präludium zu dem radikalen Sprach-Mißtrauen, das 2300 Jahre später Hugo von Hofmannsthal in seinem sog. "Chandos-Brief" 1902 als existentielle Krise beschrieb. Vgl.: Die deutsche Literatur-Texte und Zeugnisse. Bd. VII:20. Jh., 1880-1933. Hg. von W. Killy. München (Beck) 1967, S. 312-321.

2 Vgl.: J. G. Herder, Abhandlung über den Ursprung der Sprache. In: Werke. 3 Bde. (1984ff.). Hg. von W. Pross. Bd. 2. München 1987.

3 Es handelte sich ursprünglich um Humboldts sprachphilosophische Präambel zu seinem 3-bändigen Werk "Über die Kawi-Sprache auf der Insel Java" (1836-39), die 1836 als Sonderdruck erschien.

4 Zu diesem und allen folgenden Zitaten vgl.: W. v. Humboldt, Gesammelte Schriften. Hg. von der Königlich Preußischen Akademie der Wissenschaften. 17 Bände. Berlin 1903-36. Bd. IV, bes. S. 14 - Im Hinblick auf meine späteren Definitionen und Nomenklaturen identifiziere ich vorwegnehmend Humboldts 'Wirkung/Spontaneität' mit meiner 'Stil'-Konzeption und Humboldts 'Rückwirkung/Rezeptivität' mit meiner Vorstellung von 'Genre'/'Textsorte'. 
tivität, ${ }^{5}$ dem er als ein grundsätzliches Prinzip logischerweise auch Gültigkeit für die Sprache zuschreibt, ebenso wie der anderen, analogen Einsicht Humboldts in die zweite, nur scheinbar paradoxe Antinomie menschlicher Existenz aus autonomer Freiheit und simultaner Gebundenheit durch ethisch-soziale Kategorien. Beide Antinomien wirken für Humboldt in der Sprache und durch die Sprache, die durch ihre geistig-sozialen Strukturen und Charakteristika kein bloßes Zeichensystem im Sinne unserer Semiotik ist, sondern: "Die Sprache ist gleichsam die äußerliche Erscheinung des Geistes der Völker; ihre Sprache ist ihr Geist, und ihr Geist ist ihre Sprache." Ontogenetisch postuliert Humboldt: "Der Mensch ist nur Mensch durch die Sprache; um aber die Sprache zu erfinden, mußte er schon Mensch seyn...Sie geht nothwendig aus ihm selbst hervor, und gewiß auch nur nach und nach, aber so, daß ihr Organismus nicht zwar als eine todte Masse, im Dunkel der Seele liegt, aber (=sondern) als Gesetz die Funktionen der Denkkraft bedingt, und mithin das erste Wort schon die ganze Sprache antönt und voraussetzt. Wenn sich daher dasjenige (=die Sprache), wovon es eigentlich nichts Gleiches im ganzen Gebiete des Dankbaren giebt, mit etwas andrem vergleichen läßt, so kann man an den Naturinstinct der Tiere erinnern, und die Sprache einen intellectuellen (Instinkt) der Vernunft nennen."

Ich stelle diesen beiden, wie ich glaube und wie noch zu zeigen sein wird, fundamentalen philosophischen Sprachkonzeption, die alle wesentlichen Aspekte der Sprache bereits beinhalten, dennoch ergänzend zwei sprachtheoretisch-linguistische und zwei mehr pragmatische eigene Sprachdefinitionen zur Seite, aus argumentativen Gründen und um zu demonstrieren, wie auch hier methodologische Varianten die Ergebnisse variieren.

Louis Hjelmslev schreibt in den erst 1974, also mit 31jähriger Verspätung aus dem Dänischen übersetzten "Prolegomena zu einer Sprachtheorie": "Die Sprache ist dasjenige Instrument, mit Hilfe dessen er beeinflußt wird, die letzte und tiefste Voraussetzung für die menschliche Gesellschaft; aber auch der fundamentale, unentbehrliche Halt des menschlichen Individuums, seine Zuflucht in einsamen Stunden, wenn die Seele mit der Wirklichkeit ringt und der Konflikt sich auflöst im Monolog des Dichters, des Denkers, des Grüblers... Die Sprache ist keine äußerliche Begleiterscheinung, sondern ein tief in der menschlichen Seele verwobener Faden, ein Schatz an Erinnerungen, dem Einzelnen und den Generationen vererbt, ein Gewissen, das wachsam erinnert und mahnt."- "Sie (die Linguistik) muß versuchen, die Sprache nicht als ein Konglomerat von nichtsprachlichen (z.B. physikalischen, physiologischen, psychologischen, logischen, soziologischen) Phänomenen zu erfassen, sondern als ein in sich ruhendes Ganzheitsgebilde, eine Struktur sui generis."

6 Übersetzt von R. Keller/U. Scharf/G. Stölzel. München (Hueber: Ling. Reihe 9) 1974, S. 7 und 9. 
Es ist offensichtlich und braucht nicht im einzelnen hervorgehoben zu werden, daß Hjelmslev - notwendigerweise - zu wesentlichen geisteswissenschaftlichen Gedankengängen Humboldts modifizierende Analogien entwickelt, etwa zu Humboldts "energeia"-Idee und zu seinen in der Sprache reflektierten Antinomien von Wirkung und Rückwirkung, von Spontaneität und Rezeptivität, von Freiheit und Gebundenheit, aber auch zu Humboldts Vorstellung von der Sprache als ganzheitliches existentielles "Gesetz", das "die Funktionen der Denkkraft bedingt", in seinem kritischen Kommentar zur Crux der Textlinguistik.

Hans-Martin Gauger wählt in seiner Untersuchung "Wort und Sprache"7 einen interessanten, letztlich aber doch wieder auf Humboldt beziehbaren ontogenetisch-psychologischen Ansatz: "Sprache ist alles Sprachliche im individuellen Bewußtsein, das nicht nur individuell ist, alles, wovon dieses unwillkürlich annimmt, daß es in jedem anderen ebenfalls sei ..., Sprache ist ..., obgleich dem Individuum von außen her eingeübt, diesem nicht äußerlich; sie ist in ihm enthalten und in ihm zu greifen... Sprache gibt es nicht 'an und für sich'... es gibt sie nur als Besitz des individuellen Subjektes." Zu dem bei Humboldt und Hjelmslev variierten Grundgedanken vom totalen Individual-Besitz 'Sprache', der kommunikativ eingebunden ist und dadurch relativiert wird, kommt bei Gauger die Einschränkung: "obgleich dem Individuum von außen her eingeübt." Bevor ich diese Gaugersche Einschränkung anhand von empirischen Beobachtungen zur Ontogenesis von 'Sprache' kommentiere, eine eigene erste Definition von 'Sprache per se', die ich für eine Einführung in die Geistesgeschichte der deutschen Sprache benötigte: Sprache, differentia specifica des Menschen, ist der zentrale geistige Brennpunkt unserer menschlichen Existenz. Sie ist Ausdruck und Dokumentation des menschlichen Geistes; ohne Sprache gäbe es und gibt es keine geistige oder künstlerische Kultur. Sprache dient der Analyse und der Erkenntnis der inneren und äußeren Realitäten des menschlichen Seins. Sprache ist Wahr-Nehmung, Be-Zeichnung und AusDruck unserer Gedanken, Empfindungen, Gefühle, Emotionen. Sprache ist Bewußtsein des Bewußten, ist Bewußtwerden des Unterbewußten und Überbewußten innerhalb der Kategorien von Zeit und Raum. Sprache dient der Kommunikation und ist Kommunikation, mit dem Ich, dem Du, dem Wir, dem Sie, mit dem anderen und dem Anderen. Sie ist Organisation, Struktur und Form unseres Wissens, Denkens und Willens, unseres Empfindens und Fühlens.

Was diese meine - zugegebenerweise didaktisch funktionalisierte - Sprachauffassung von den zuvor herangezogenen unterscheidet, ist eine - selbst gegenüber Hjelmslev - stärker betonte Historizität der Sprache, die - wie der Mensch selbst und notwendigerweise mit ihm zusammen - den Kategorien von Raum und Zeit unterworfen ist. Außerdem spreche ich bereits implizite - über den Begriff der 'Kultur' und ihrer geistig-künstlerischen schriftlichen Ausdrucksformen - die von mir später zu diskutierenden 'Sprache'-'Text'-Bezüge an. 
Schließlich benötigte ich - für meine Distinktion von 'Text' und 'Textsorte'- eine zweite Eingrenzung des Begriffs 'Sprache' im Hinblick auf die 'Textsorte' Phraseologismus, und zwar nicht mehr für 'Sprache per se' als differentia specifica, sondern für 'Sprache' als konkretes einzelsprachliches Phänomen: Was die gemeinsame Grundstruktur aller 3000 bis 4000 menschlichen Einzelsprachen ausmacht, kann man als 'offenes' und paradoxerweise zugleich absolut 'geschlossenes' Zweiklassensystem aus 'Lexikon' und 'Syntaktik' bezeichnen. Das heißt, jede der menschlichen Einzelsprachen besitzt als erste System-Klasse ein 'Lexikon' (zu gr. "lexis"= Wort/Rede und gr. "lexikon"= Wörterbuch sowie gr. "legein"/lat. "legere"= sammeln, auflesen, lesen), worunter man die Gesamtheit aller Wörter einer gegebenen 'Sprache' zu verstehen hat. Unter der zweiten System-Klasse 'Syntaktik' (zu gr. "syn"=zusammen, zugleich und gr. "syntaxis"= Anordnung sowie lat. "tactus"= Berührung; Gefühl) verstehe ich alle formalen Relationen der Sprachzeichen zueinander, alle logisch erlaubten und denkbaren Verbindungen der 'Lexikon'-Wörter zu Worten, Wortgruppen und Sätzen unter den Aspekten der äußeren Form, der inneren Struktur, der intentionalen Funktion und der Semantik. Dieses Zweiklassen-System aus 'Lexikon' und 'Syntaktik' ist 'offen', weil jede 'Sprache' ein historisch gewachsenes und historisch bedingtes System der Kommunikation und der Realitätsanalyse ihrer Sprecher ist, und zwar im Sinne meiner vorgegebenen Definition von 'Sprache per se'. Das heißt, was die Menschen einer gegebenen Sprachgemeinschaft vor 1000 oder noch vor 50 Jahren zu kommunizieren oder als äußere bzw. innere Realitäten ihres Daseins zu analysieren hatten, hat sich inzwischen, von den Kategorien Raum und Zeit determiniert, gewandelt, z.T. grundsätzlich verändert. Sachverhalte wie die Kaiserkrönung Ottos I. im Jahre 962 unterscheiden sich grundsätzlich von der Vereidigung des neuen SPD-Kanzlers Willy Brandt im Jahre 1969; Wörter wie "minne" und "staete", "veimen/feimen" und "ver/verje", wie "Kiepe" und "Kien", "Blust" und "Blümchenkaffee" sind längst, d.h. seit Jahrhunderten oder erst seit Jahrzehnten, keine im Sprachlichen zu analysierenden und zu realisierenden inneren und äußeren Realitäten unseres Daseins mehr. Mit anderen Worten: Das obsolete, unverständliche, weil auf keine präsente Realität mehr bezogene Wortmaterial des 'Lexikons' ist dem 'offenen' System unserer aktiven Gegenwartssprache herausgefallen; dafür sind andere Wörter, die unseren Großeltern wie böhmische Dörfer vorgekommen wären, durch eine stets 'offene Tür' in unser 'Lexikon' eingezogen, wie etwa: Computer, Software, Softie; Taschenrechner, Junkie und Aids. Und auch die moderne Syntax des Deutschen ist im Magazin "Spiegel" nicht mehr, was sie einst im "Nibelungenlied" oder bei Schiller war, d.h. auch in der System-Klasse 'Syntaktik' funktioniert die 'Offenheit' des Systems, die aus der jeweiligen Gegenwartssprache Altes eliminiert und dafür Neues aufnimmt. Konkret bedeutet das etwa, daß die chiastisch verschränkende Apokoinu-Struktur des 12. bzw. 18. Jahrhunderts ("do spranc von dem gesidele her Hagene also sprach." - "Was sein Pfeil erreicht, das ist seine Beute, was da fleucht und kreucht.") ersetzt wird durch Satzfragmente bzw. verselbständigte Glied- 
sätze ("Wer, Heiner Müller, der Dichter? Ein Gigant. Das Leben, die DDR? Weil es schwer war.")

Anderseits ist jedoch jede Einzelsprache - und die deutsche Sprache wohl in besonderem Maße - etwas 'absolut geschlossenes' in ihrem historischen Gewachsensein. Was ich mit dem Ausdruck "absolut Geschlossenes" meine, ist die Tatsache, daß nichts, auch nicht das kleinste Jota, aus 'Lexikon' und 'Syntaktik' unserer Sprache wieder verlorengeht, sobald es einmal kreiert und im System unserer Sprache gespeichert worden ist. Mit anderen Worten: Was im Deutschen vor 200 Jahren (Goethe und Schiller), vor 460 Jahren (Luthers Gesamtbibel-Übersetzung, 1534), vor 660 Jahren (Meister Eckehart, die Sprachschöpfungen der Mystik), vor 780 Jahren (1. deutsche Klassik: Hartmann, Wolfram, Gottfried, Walther), ja selbst vor über 1200 Jahren (althochdeutsches "Hildebrandslied") bei den damaligen Zeitgenossen in 'Lexikon' und 'Syntaktik' hochaktuell war, ist zwar zum größten Teil für unsere Alltags- und Gegenwartssprache obsolet und inaktiv geworden, es ist jedoch im "absolut Geschlossenen" des historisch gewachsenen und ständig weiter wachsenden Gesamt-Wortschatzes, der Gesamt-Syntaktik der deutschen Sprache latent in höchst viriler Weise auf Abruf potent geblieben, permanent gespeichert. Diese latent stets präsente, auf Abruf verfügbare Potenz und Virtualität der historischen Schichten des deutschen Gesamt-Wortschatzes und der deutschen Gesamt-Syntaktik zeigt sich zum einen bei so eminenten Autoren wie Thomas Mann ("Doktor Faustus"; "Der Erwählte") und Günter Grass ("Der Butt"; "Das Treffen in Telgte"), um nur zwei bekannte Beispiele zu nennen. Zum anderen verwendet jeder Benutzer des Deutschen jene in Phraseologismen historischer Provenienz gespeicherte Bildlichkeit des "absolut Geschlossenen" unseres Sprachsystems. Denn auch die im Goetheschen Sinne nur noch "ererbte" und nicht mehr "erworbene", laut Meister Eckehart nicht mehr "begriffene", historisch-idiomatische Bildlichkeit des Deutschen wird so lange weiterbenutzt, wie dadurch in unserer Gegenwart für den Autor und für den Rezipienten ein gerade noch verständliches semasiologisches Zeichen gesetzt wird, wobei allerdings kein wirkliches 'Erwerben' oder 'Begreifen' der semasiologischen 'Bedeutung' zwischen den sprachlich Kommunizierenden eine Rolle spielt, sondern lediglich eine allgemeine Übereinkunft der Sprachbenutzer über eine oberflächlich verstandene, vage semasiologische Chiffre.

Es wird sich später zeigen, wie diese einzelsprachliche Antinomie aus 'Offenheit' und 'Geschlossenheit' bei der Ausbildung und Eingrenzung von 'Textsorten' mitwirkt. Ich greife zunächst auf die ontogenetischen Aspekte der 'Sprache'-Definitionen von Humboldt, Hjelmslev und Gauger zurück, weil der ontogenetische Vorgang der PrimarRealisierung von 'Sprache' als 'Rede' des Kindes für meine Distinktionen von 'Sprache', 'Rede', 'Text', 'Genre' und 'Textsorte' relevant ist.

Der Unterschied zwischen der präzisen Feststellung Humboldts: "Der Mensch ist nur Mensch durch Sprache ... Sie geht nothwendig aus ihm selbst hervor ..." ${ }^{8}$ und Hjelm- 
slevs Einschätzung der 'Sprache' als "auch der fundamentale, unentbehrliche Halt des menschlichen Individuums" ${ }^{\prime 9}$ ist ein wesentlicher. Während Humboldt die sprachliche Ontogenesis radikal individualisiert, ist die sprachliche Autonomie des Individuums bei Hjelmslev eingeschränkt durch ihre Festlegung als "letzte und tiefste Voraussetzung für die menschliche Gesellschaft" sowie relativiert und konditionalisiert als ein dem Individuum "auch" verfügbarer "Halt", "wenn die Seele mit der Wirklichkeit (der Kollektivität) ringt und der Konflikt sich auflöst im Monolog". ${ }^{10}$ Für Gauger ist 'Sprache' zwar ein "Besitz des individuellen Subjektes", sie ist "im individuellen Bewußtsein", aber sie ist ihm keine autonome Potenz oder Kreation des Individuums, sondern etwas Heteronomes, "dem Individuum von außen her eingeübt". ${ }^{11}$ Und ihr entscheindendes Charakteristikum ist, daß sie "nicht n u r individuell ist". Damit wird 'Sprache' durch eine paradoxe Antithetik bestimmt aus 'Besitz und Inhalt des individellen Subjekts und Bewußtseins' (Paraphrase) einerseits und ihrer a priori angesetzten kollektiven Genesis und Kollektivierung als Kommunikationsvehikel andererseits.

Die Tatsache, daß es immer wieder Zwillinge, Geschwister, enge Freunde gegeben hat - zuletzt die Zwillingsschwestern Jennifer und June Gibbons ${ }^{12}$-, die sich weigerten, sprachlichen Konformitätszwängen ihrer Sprachgemeinschaft nachzugeben und statt dessen ihr eigenes, der Gemeinschaft entfremdetes Idiom kreierten, sprachen, schrieben, scheint Wilhelm von Humboldt zu bestätigen, Hans-Martin Gauger zu widerlegen. Man kann in diesem Zusammenhang auch an die in ihrer menschlichen Geistigkeit 'verirrten' Individuen denken - und 'Sprache' ist ja Ausdruck und Dokumentation des menschlichen Geistes, wie auch Humboldt betont -, deren 'Sprache' "idios, idiotikos", d.h. eigentümlich-eigen, geworden ist. (Man denke an Hölderlin, C.F.Meyer, Georg Trakl.) Dokumentarischer sind Beobachtungen zur sprachlichen Ontogenesis der 1 1/2jährigen Esther Laura Franke. ${ }^{13} \mathrm{Im}$ Vollzug Humboldtscher Sprachautonomie bezeichnet das Kind mit dem arbiträr gesetzten Kollektivum "Tockedas" alle gefiederten Freunde, die nicht "piep, piep" machen, also das Hausgeflügel der Gänse, Enten, Tauben und Hühner. Ebenso autonom-arbiträr gesetzt ist die Bezeichnung "Tockedis" für Tannenzapfen, obwohl hierbei ein für uns kaum zu rationalisierendes formales Bildungsprinzip mittels alliterierender und ablautender Suffigierung des Stammes "Tocke-" angewandt ist. Nach dem Prinzip der Sprachökonomie verfährt Esther, indem sie die früher von ihr benutzten alliterierenden vier Einzel-Lexeme heterogener Provenienz "Schlüssel", "Schuhe", "Schoß" und "Schnuller" durch das wiederum arbiträre, doch nunmehr nicht mehr autonome Pseudo-Kollektivum "Soße" ersetzt, das immerhin eine assonantische

11 Siehe Anm. 7.

12 Vgl.: M. Wallace, Als Jennifer starb, war June erlöst. Übers. von G. Kramper. In: ZEITmagazin 34(1994, 198), S. 20-25. 
Alliterationsbeziehung zu den von ihr kollektivierten Einzel-Lexemen aufweist. Das Kleinkind verfügt außerdem in seinem phonetisch adaptierten Lexikon heteronomer Wörter über die Lexeme "Beer" für Brombeere und "Mate" für kleine Kirschtomaten. Da Esther Brombeeren, Kirschtomaten und Obst überhaupt besonders gerne ißt, bildete sie aus "Beer" und "Mate" das neue autonome Kompositum "Beermate", um damit die erstmals in ihrem 1 1/2-jährigen Dasein als grüngelb-rundes Perzeptions-Phänomen auf sie einwirkenden Weintrauben sprachlich-kognitiv 'wahr'-zunehmen und - durch konnotative Geschmacksanalogien zu "Beer" und "Mate" motiviert - von ihren Eltern zu verlangen.

Diese ontogenetischen Beobachtungen am Falle der Esther Laura Franke zeigen, daß die absolute sprachliche Individual-Autonomie Humboldts zwar als sprachphilosophische Idee und als geistesgeschichtliches Ideal-Axiom durchaus einleuchtend und nachvollziehbar ist. Denn das Kind hat diese sprachliche Individual-Autonomie ja tatsächlich praktiziert; allerdings nur partiell praktiziert und praktiziert innerhalb der offenbar strukturimmanenten, dem Kinde absolut unbewußten, doch intuitiv benutzten generativen Parameter der objektivierten Einzelsprache, auf die ich bereits kommentierend hingewiesen habe. Außerdem wird das Kind schon jetzt hinsichtlich seines Lexikons von den kollektiven Konformitätszwängen seiner Sprachgemeinschaft in seiner individuellen Sprach-Autonomie begrenzt und relativiert. Es wird also letzten Endes den individuellen sprachlichen Autonomie-Freiraum, den ihm die liebevolle Zuwendung der Eltern gewährt, indem sie alle autonom-arbiträren kindlichen Idiotismen als Intelligenzindizien begrüßen und verständnisvoll interpretieren, verlassen müssen, um - im Sinne der Antinomien Humboldts, nach dem bereits eddischen Motto "Den Menschen freut der Mensch." ${ }^{14}$ und dem humanen Bequemlichkeitssyndrom gehorchend - als Zoon politikon kollektiv zu existieren und das heißt zu kommunizieren. Es sei denn, Esther Laura Franke realisiert ihre sprachliche Autonomie-Potenz als asoziales Individuum, wie die Zwillinge Gibbons, oder wird geistig-existentiell "idiotikos", wie Virginia Woolf.

Wir müssen also einräumen, daß den ontogenetischen Sprach-Aspekten Hjelmslevs und Gaugers neben der Humboldtschen Autonomie-Idee ebenfalls eine partielle Relevanz für das Gesamt-Phänomen 'Sprache' zuzuschreiben ist, obwohl Gaugers von "außen kommende Einübung" zu hinterfragen wäre und, auch zeitlich, von sekundärer Bedeutung ist, weil sie die - wie immer relativierte und modifizierte - prinzipielle Sprach-Autonomie des Individuums nicht beeinträchtigt. Grundsätzlich hat sich wiederum die erstaunliche Komplexität des Phänomens 'Sprache' - selbst auf der ontoge-

Vgl.: Edda. Übertragen von F. Genzmer. Bd. 2: Götterdichtung und Spruchdichtung. Thule: Altnordische Dichtung u. Prosa, Bd. 2. Düsseldorf/Köln 1963, S. 127, Str. 35: "Jung war ich einst, einsam zog ich, da ward wirr mein Weg; glücklich war ich, als den Begleiter ich fand: den Menschen freut der Mensch." 
netischen Primarstufe - gezeigt, die Hjelmslev "als ein in sich ruhendes Ganzheitsgebilde, eine Struktur sui generis" angesprochen hat.

Von dieser Vorstellung der 'Sprache' als "in sich ruhendes Ganzheitsgebilde", das alle potentiellen Ausformungen als 'Rede', 'Text', 'Genre' und 'Textsorte' beinhaltet und subsumiert, die lt. Humboldt "als Gesetz die Funktionen der Denkkraft bedingt", "nicht sowohl wie ein todtes Erzeugnis, sondern weit mehr wie eine Erzeugung"3) gehe ich im folgenden aus. Dabei setze ich als Axiom, daß diese allumfassende und komplexe 'Sprache an sich', wie sie von allen sprachphilosophischen und sprachtheoretischen Überlegungen und Konzeptionen - meine eigenen eingeschlossen - erfaßt und vorgestellt wird, nur als philosophisch-theoretisches Konstrukt, als Platonische Idee, nicht als zeit-räumlich gebundenes Kantsches Phänomen gibt. Außerdem ist festzuhalten, daß die 'Sprach-Idee' jener philosophisch-theoretischen Überlegungen sich exklusiv auf 'Sprache' als etwas potentiell Gesprochenes bezieht, also auf etwas, was bei Ferdinand de Saussure als "parole" (Sprechen, Sprachverwendung, performance) und als "langage" (menschliche Rede, menschliche Sprechfähigkeit) umschrieben wird. Die Frage ist also: Wie verhält sich dieses so definierte potentiell Gesprochene, diese abstrahierte, mit der Humboldtschen dynamisch-spontanen Kraft der "energeia" ausgestattete 'Sprache' zu dem Begriff 'Text'? Ist jene 'Sprache' die kompositionelle Gesamtheit, die Universalität aller potentiellen 'Texte'? Oder sind 'Sprache' und 'Text' zwei divergierende, disjunktive Konzeptionen; bzw. ist 'Text' ein phänomenologischer oder der einzige phänomenologische Aspekt von 'Sprache'? Die Antwort auf diese Fragen ergibt sich aus dem Wie des Objektivationsprozesses von 'Text', sie ergibt sich aus einer generativen Definition von 'Text'.

Bevor ich die eben gestellten Fragen durch meine angesagte Definition von 'Text' beantworte, möchte ich zur Eingrenzung und Kontrastierung aus der - wie eingangs angedeutet - beliebigen Zahl divergierender linguistischer 'Text'-Definitionen Weniges selektiv referieren und kommentieren:

Klein und von Stutterheim erfanden für ihre 'Text'-Definition 1991 den Terminus "Gesamtvorstellung", womit sie ziemlich genau das meinen, was André Jolles schon 1930 als "Geistesbeschäftigung" festlegte, nämlich ein jeweils spezifisches geistigmentales, sich folglich sprachlich realisierendes Konzept, das für die thematische, globale und lokal-formale Struktur eines 'Textes' verantwortlich ist: "A text... differs in two respects from an arbitrary collection of utterances: A. It obeys certain global constraints which primarily result from the fact that the utterances in their entirety serve to express, for a given audience and to a given end, a complex set of information, a 'Gesamtvorstellung'... The nature of the 'Gesamtvorstellung', on the one hand, and the specific purpose the speaker has in expressing it, on the other, impose special constraints on the overall organization of the text. B. The way in which the text proceeds from one utterance to the next obeys local constraints, depending on which information is introduced, maintained or elaborated on... Each utterance selects a segment from the 'Ge- 
samtvorstellung' and puts it into words." ${ }^{15}$ Für Klein/von Stutterheim ist 'Text' damit Gesprochenes, das ein Sprecher ("speaker") für ein bestimmtes Publikum zu einem bestimmten Zweck ("for a given audience and to a given end") ausspricht ("express"/es), wobei der 'Text'-Sprecher logischerweise die textuale Sprachobjektivation steuert; Sprecher, Publikum und 'Text' sind kopräsent.

Dem widerspricht K. Ehlich in seinem Aufsatz "Zum Textbegriff". Für Ehlich ist 'Text' noch immer etwas Gesprochenes. Aber 'Text' bedeutet ihm eine zum Sprechakt parallele und davon quantitativ verschiedene kommunikative Größe. Denn der "einfache Sprechakt umfaßt normalerweise einen Satz. Demgegenüber ist der Text ... eine übersatzmäßige Einheit." - "Der Text ist nicht mit dem Sprecher und Hörer kopräsent, sondern er verselbständigt sich beiden gegenüber." ${ }^{16}$ Wiederum verweisen diese 'Text'Eingrenzungen auf André Jolles, der seine 'Einfachen Formen' als hypersyntaktische vorliterarische 'Text-Archetypen' verstand, "die sich, sozusagen ohne Zutun eines Dichters, in der Sprache (von) selbst ereignen", 17 mittels der zugehörigen 'Geistesbeschäftigung', und die folglich weder grammatischen (da hypersyntaktisch) noch poetologischen (da vorliterarisch) Kategorien unterworfen sind. Die Idee einer Verselbständigung des Gesprochenen findet sich freilich erstmals - zusammen mit einer Vorwegnahme des 'globalen Konzepts'- in Heinrich von Kleists "Über die allmähliche Verfertigung der Gedanken beim Reden": "Aber weil ich doch irgend eine dunkle Vorstellung habe, die mit dem, was ich suche... in einiger Verbindung steht, so prägt, wenn ich nur dreist damit den Anfang mache, das Gemüt, während die Rede fortschreitet, in der Notwendigkeit, dem Anfang nun auch ein Ende zu finden, jene verworrene Vorstellung zu völliger Deutlichkeit aus, dergestalt, daß die Erkenntnis, zu meinem Erstaunen, mit der Periode fertig ist..." Jahrzehnte später von Humboldt wieder in nuce philosophisch-anthropologisch ausgedrückt wird (s.o.) und die auch in der modernen Sprachphilosophie eine Rolle spielt. ${ }^{19}$

Ein generalisierendes, von der Semiotik beeinflußtes 'Text'-Verständnis präsentiert K.Hausenblas, wenn er behauptet, es gäbe drei 'Text'-Arten, nämlich: 1. "linguale

15 W. Klein/Ch. v. Stutterheim, Textstructure and Referential Movement. In: Sprache u. Pragmatik 22(1991), S. 1-32; s. If.

16 K. Ehlich, Zum Textbegriff. In: Text-Textsorten-Semantik. Linguistische Modelle u. maschinelle Verfahren. Hg. von A. Rothkegel/B. Sandig. Hamburg(Buske) 1984, S9-25; s. 13ff. u. 17.

17 Vgl.: A. Jolles, Einfache Formen. 2 Tübingen (Niemeyer) 1958,bes. S. 10 und A. Jolles/W. Porzig, Rätselforschungen. In: Fs. Sievers (Halle 1925), S. 632-60, bes. S. 633, 646.

18 H. v. Kleist, Werke in einem Bande. Hg. von H. Sembdner. München (Hanser) 1966, S. 810-14; s. 810 .

19 Vgl. etwa: F. Kainz, Psychologie der Sprache. Bd. 3. Stuttgart 1963, S. 121, wo darauf verwiesen wird, $\mathrm{daB}$ der Inhalt, die kommunikative Planung, einer mündlichen oder schriftlichen Textaussage zum großen Teil erst bei der mündlichen oder schriftlichen sprachlichen Realisierung selbst formuliert wird, daß Denken und sprachliche Äußerung des Gedachten also synchron ablaufen und nicht diachron. 
Texte (immer mit paralingualen Elementen)" - 2. "außerlinguale Texte (sprachlose Comics)" - 3. "gemischte Texte (entweder mit Dominanz von lingualen oder außerlingualen Elementen)". ${ }^{20} \mathrm{Daß}$ für mich "außerlinguale" bzw. "sprachlose Texte" Contradictiones in adiecto, deshalb als Definitionen inakzeptabel sind, "Comics" zudem aus sprachlogischen Gründen keine 'Texte' sein können, sei meiner 'Text'-Definition vorweggenommen. Selbst Hausenblas identifiziert jedoch - schließlich bedeutet lat. "lingua": Zunge, dann metonymisch: Rede und Redegabe, schließlich als Metalepsis: Sprache - für seine Definition 'Text' mit dem Gesprochenen, obwohl er das Gesprochene grundsätzlich mit andersartigen, auch optischen Sinnesreizen koppelt (man bemerkt den multimedialen Einfluß), letztere sogar als 'Comic-Text' verabsolutiert und karikiert.

Ich beschließe meine Teichskopie mit 'Text'-Definitionen, die mir wegen ihrer Kürze und Prägnanz, wegen ihrer Konzentration auf einen singulären Aspekt, auch wegen ihrer Nähe zu meiner eigenen Definition relevant erscheinen: E.Agricola fordert "relative Abgeschlossenheit" ${ }^{21}$ als 'Text'-Kriterium; G.Klimonow "überlegt" in ihren "definitorischen Kriterien (!) des Textbegriffes", daß "der Text als Ganzes in kommunikativer Hinsicht vollständig zu sein hat"; ${ }^{22}$ M.A.K.Halliday und R.Hasen erklären den Begriff 'Text' als "used in linguistics to refer to any passage, spoken or written, of whatever length, that does form a unified whole", 23 wobei man "unified whole" nicht als "Abgeschlossenheit" übersetzen darf, sondern als "in sich schlüssiges Ganzes". Das verlangt die Logik des Englischen und die Tatsache, daß "Abgeschlossenheit" etwas Fertiges, Unzugängliches meint, das keine Kohärenz-Affinität, keine Intertextualität aufweist. In dieser britischen Definition erscheint erstmals ein 'Text'-Kriterium ("...or written"), das sonst ganz vernachlässigt wurde: die Schriftlichkeit des 'Textes'.

Auf die Gefahr hin, meine eigene 'Text'-Definition im voraus zu diskreditieren, zitiere ich noch C.Knobloch, "Zum Status und zur Geschichte des Textbegriffes" (1990): "('Text' gehört) zu den aspektheterogenen und offenen Grundbegriffen der Sprach- und Literaturwissenschaften, die nicht abschließend definiert werden können, weil ihre theoretische Produktivität vorwiegend heuristischer Natur ist und sich nur innerhalb bestehender Axiomatisierungen entfaltet." Dieser Einsicht folgt aber wenig später die Auffassung, 'Text' sei ein "materiell abgeschlossenes und schriftlich wiedergegebenes Sprachwerk". ${ }^{24}$

20 K. Hausenblas, Zu einigen Grundfragen der Texttheorie. In: Probleme der Textgrammatik Il (Studia grammatica XVIII). Hg. von F. Daneš/D. Viehweger. Berlin (Akademie) 1977, S. 147-58, s. 148.

21 E. Agricola, Text-Textaktanten-Informationskern. In: ebd., S. 11-32, s. 11.

22 G. Klimonow, Überlegungen zu einigen definitorischen Kriterien des Textbegriffes. In: ebd., S. 18184 , s. 183.

In: LiLi 77(1990), S. 66-87, s. 68f. 
Ich halte es bei dem Begriff 'Text' mit der Schriftlichkeit und als Philologe (zu gr. "philos"= Freund, "philein"= lieben und "logos"= Vernunft, Wort, Rede, Berechnen, Grund etc.) mit der "etymologia" (zu gr. "etymos"= wahrhaft, wirklich und "to étymon"= die ursprüngliche wahre Bedeutung). Das deutsche Wort 'Text' ist spätmittelhochdeutsch aus dem lateinischen Wort "textus" entstanden; und das bedeutete: Gewebe oder Geflecht; Verbindung, Zusammenhang; zusammenhängender Inhalt einer Rede oder einer Schrift; daher auch der Name "Textura" für die spitzbogig-verwobene, prunkhafte gotische Buchschrift, in der die damaligen bedeutendsten und bedeutsamsten Objektivationen der 'Sprache' im Herderschen Sinne 'gebannt', d.h. zur Dauer gebracht, 'textualisiert' worden sind. Außerdem gehört zu dem deutschen Wort 'Text' das lateinische Verb "texere" mit dem "etymon": fügen, planvoll-harmonisch zusammenfügen. Mit anderen Worten: Wo immer das lateinische Lehnwort 'Text' in allen gegebenen abendländischen Volkssprachen auftritt, ist es kulturell-funktional und historischzeitlich unlöslich verbunden mit der Genesis einer volkssprachlichen Schriftkultur. 'Text' ist schriftlich gewordene 'Sprache', ist das Fundament, das Wesentliche, die Struktur, die entscheidende Dokumentation jeder Schriftkultur.

Deshalb, denn 'Sprache' ist "logos", können wir einen 'Text' lernen, hersagen, herunterbeten, vorlesen, rezitieren, vortragen, interpretierend vortragen; wir können einen 'Text' konzipieren, zusammenstellen, kürzen, erweitern, entwerfen, überarbeiten, redigieren, korrigieren, herausgeben; wir können ihn verstehen, begreifen, deuten, analysieren, interpretieren. Es gibt den 'Text' eines Liedes, einer Oper, einer Rede, eines Vortrages, eines Romans, eines Gedichtes, eines Dramas, eines Filmtextbuches. Wir können eine deutliche Sprache reden oder sprechen. Doch wir können - obwohl doch scheinlegitime Figura etymologica -, weil wie "nasses Wasser" oder "alter Greis" ein sprachlich alogischer Pleonasmus, keine "Rede reden". Und wir können keinen "Text reden", lediglich als Texter 'Texte' texten. Denn "Reden" einerseits - als eine akustischdynamische, folglich transitorische Ausformungs-Kategorie des philosophisch-theoretischen Konstrukts 'Sprache'- und 'Text' andererseits - als Makro-Konzeption einer konkreten schriftlichen Ausformung, als eine wegen ihrer Schriftlichkeit atransitorische, Permanenz anstrebende Ausformungs-Kategorie des gleichen Konstrukts schließen sich als Contradictio in adiecto im "logos" sprachimmanenter Strukturen gegenseitig aus. Meine Beispiele zeigen auch, wie sich der "logos" kategorialer MakroStrukturen der 'Sprache' in den Mikro-Strukturen sprachlicher Pragmatik analogisiert.

Zur generativen Definition meiner 'Text'-Vorstellung gehören als notwendige konnotative Ergänzungen das lateinische Wort "stilus" und dessen deutsche Entsprechung "Griffel". "Stilus" und "Griffel" - im Computer-Zeitalter nur noch symbolisch zu verstehen, obwohl bei aller elektronisch mechanisierten Umsetzung realiter doch existent drückten bzw. drücken das als 'Text' aus, was die thematisch-geistige, aus der 'Sprache' kommende "energeia" der individuellen Sprach-Beherrschung mittels der Hand nach dem wirkenden Gesetz der Denk- und Sprachkraft determinierte und tatsächlich heute noch - selbst auf dem kollektivierenden Computer - determiniert. Das entscheidende 
Instrumentum der 'Text'-Ausformung aus der kompositionellen Universalitäts-Kategorie der 'Sprache' ist mir also der 'Stil'. Ohne 'Stil' bleibt 'Text' integrierter Bestandteil der Kategorie 'Sprache'. Denn "Griffel" (zu ahd. "grifan", mit der Werkzeugsilben-Suffigierung "-il"= greifen, begreifen), als "stilus"-Entsprechung und als Ding-Symbol des 'Begreifens' sprachlicher Strukturen, und "Hand", als archetypisches metonymisches Symbol des Individuums, des Ich, zu dem Geist und damit 'Sprache' als konstituierende Wesensmerkmale gehören, verweisen auf eine notwendige kooperative Leistung der geistigen und der sinnlich-physikalischen Komponenten des Menschen im Sprachlichen. Mit 'Stil' bezeichne ich mithin einen thematisch determinierten Akt kreativer sprachlicher Autonomie des menschlichen Individuums in den quantitativen und allen sonstigen Bereichen der 'Sprache' nach einheitlich-kategorialen Selektionsprinzipien sowie das textimmanente Resultat dieses Aktes. Damit ist 'Stil' im eigentlichen Sinne 'bewußte Sprache', da 'Sprache' ohne 'Stil' unbewußte Repetition vorgegebener Sprach-Muster bleibt. Zu diesem 'bewußten' Akt des 'Stils' gehört folglich auch die 'bewußte' und 'gewußte', also kognitiv-integrierte und selektiv-einsichtige Verwendung von 'stilistischen Fertigteilen', d.h. 'Textsorten' (s.u.), obwohl es sich dabei letztlich um einen plagiatorischen Vorgang handelt, wobei die 'Textsorten' sich mit der unendlichen Tastatur eines Klavieres vergleichen lassen, auf deren Mithilfe der durchschnittliche 'Stil'-Pianist für seine Eigenkompositionen angewiesen ist.

Die qualitativen Kriterien stilistischer Selektionsprinzipien hat Goethe 1789 in der Abhandlung "Einfache Nachahmung der Natur, Manier, Stil" zwar für die Kunst (in Anlehnung an die Aristotelische "Mimesis"), aber durchaus auf das menschliche Individuun per se übertragbar (s.u.), so formuliert: "Gelangt die Kunst (= das Individuum) durch Nachahmung der Natur..., durch genaues und tiefes Studium der Gegenstände selbst endlich dahin, daß sie (= es) die Eigenschaften der Dinge und die Art wie sie bestehen, genau und immer genauer lernt, daß sie $(=e s)$ die Reihe der Gestalten (= Ausformungen, Phänomene) übersieht und die verschiedenen charakteristischen Formen nebeneinander zu stellen und nachzuahmen weiß, dann wird der Stil der höchste Grad, wohin sie (= es) gelangen kann... So ruht der Stil auf den tiefsten Grundfesten der Erkenntnis, auf dem Wesen der Dinge, insofern uns erlaubt ist, es in sichtbaren und greiflichen Gestalten (s.o.) zu erkennen..." 25

Man wird und kann gegen meine Individual-Definition der Kategorie 'Stil' einwenden, daß es doch einen National-, einen Zeit-, einen Epochen-, einen Gattungsstil etc. gäbe. Sicher gibt es diese a priori-Lexeme; aber es gibt sie nur als recht vage Abstraktionen der Summen aller Individual-'Stile' einer bestimmten Nation, einer bestimmten Zeit, Epoche, Gattung usw., wobei man nicht weiter gekommen ist - weil man nicht weiter kommen kann -, als die 'Stil'-Individualitäten einer X-beliebigen Zahl stilautonomer Autoren durch statistische Manipulationen auf den kleinsten, d.h. erstaun- 
lich ungenauen gemeinsamen Nenner zu bringen. National-, Zeit-, Epochen-, Gattungsstil werden durch diese statistischen Determinierungsversuche nicht zu auf Eigenleistungen beruhenden, qualitativ erfaßbaren Größen. Denn das 'schöpferische Kollektiv' gibt es nicht, weder als räumliches noch als zeitliches Phänomen. Anders ausgedrückt: Der literarhistorische Streit um die oder den Nibelungenlied-Dichter ist inzwischen längst zugunsten des Singulars entschieden worden. ${ }^{26}$ Den 'stilistischen Griffel' oder "stilus" kann man eben nur mit einer Hand führen. Und wenn Autoren wie Arno Holz und Johannes Schlaf 1889 versucht haben, es mit zwei Händen zu tun, so ist dabei nur eine platte, stillose Ablichtung äußerlicher, 'naturalistischer' Alltagsrealitäten herausgekommen, die heute niemand mehr interessiert, weil das 'Stil'-bezogene "Wesen der Dinge" Goethes fehlt. Aufgrund der von Humboldt als Antinomien erfaßten (s.o.) Bedingtheiten der - die 'Sprache' einschließenden - Gesamtexistenz des Menschen, Bedingtheiten, die Humboldt konstituiert aus Wirkung (also: 'Stil') und Rückwirkung (also: 'Genre/Textsorte'), aus Spontaneität (also: 'Stil') und Rezeptivität (also: 'Genre/Textsorte'), aus Freiheit (im gesamten Lebens-'Stil' des Menschen, einschließlich seines 'Rede'- und 'Text'-'Stiles') und aus simultaner Gebundenheit durch historisch-ethisch-soziale Kategorien sowie durch historisch gewachsene und bedingte Rahmen-Strukturen von 'Sprache', 'Rede' und 'Text' (auf letztere komme ich bei meiner 'Textsorten'-Definition zurück), gibt es natürlich gewisse Parameter und Einschränkungen, über die sich der autonome 'Stil'-Wille des Individuums nicht hinwegsetzen kann - oder nur in Ausnahmefällen hinwegsetzen kann. ${ }^{27}$

Und es sind eigentlich diese zeitlich-räumlich variierenden Parameter und Einschränkungen selbst, die im Bereich der 'Gattungen' als 'Stil'-Merkmale herhalten müssen. Nun gibt es neben den drei Grundgattungen Epik, Lyrik, Dramatik eine fast beliebige Vielzahl von Untergattungen, die Goethe "Dichterarten" nennt - unter Betonung der Gegensätzlichkeit von "Naturform"/Grundgattung und "Dichtart"/Untergattung. Es gibt Heldenlieder, Zaubersprüche, Reimchroniken, Spielmannsepen, Artusepen, Minnelieder, Spruchdichtung, Predigten, Fachprosa, Romane, Novellen, Tragödien, Komödien, Elegien, Oden, Fabeln, Märchen, Rätsel usw. Für Goethe und für Emil Staiger $^{28}$ sind die drei "Naturformen"/Grundgattungen anthropologisch (Goethe) bzw. 'stilistisch' (Staiger) bestimmt. Wobei Staiger einen zu meinem disjunktiven 'Stil'-Begriff verwendet, analog zu den drei Zeit-Kategorien Vergangenheit, Gegenwart, Zukunft. Der 'Stil' des Lyrischen ist ihm: Erinnerung, des Epischen: Vorstellung/Ver-

26 H. Fromm, Der oder die Dichter des Nibelungenliedes? In: Accademia Nazionale dei Lincei: Atti dei Convegni Lincei 1. Roma 1974, S. 63-77.

27 Bei diesen Ausnàhmefällen uneingeschränkten oder fast uneingeschränkten autonomen Stils denke ich etwa an Wolfram von Eschenbach, Gottfried von Straßburg; Meister Eckehart; Gottfried Benns "Statische Gedichte2; die 'Konkrete Poesie' Morgensterns, der Dadaisten Ball, Schwitters und Arp, Gedichte von Mon, Gomringer und Jandl. 
gegenwärtigung, des Dramatischen: Spannung/pathetische Zielstrebigkeit. Das heißt, die "Dichtarten"/Untergattungen - die ich im folgenden 'Genres' nenne (zu lat. "genus, generis"= Klasse, Geschlecht, Art, Sorte) - werden wiederum in der sogenannten 'Gattungspoetik' unter drei abstrahierende a priori-Kategorien subsumiert, die als distanzierte theoretische Abstrakta - per definitionem meam - mit 'Stil' wenig, nur aus großer Ferne zu tun haben, weil sie mit dem eigentlichen 'stilistischen Akt' des autonomen 'Text'-Autors nichts zu tun haben. Doch jedes 'Genre' ist mir stilistisch determiniert, durch den 'Stil' seiner Einzel-'Texte'. Und natürlich schränke ich den Terminus 'Genre' nicht auf literarische 'Text'-Klassen ein; auch pragmatische 'Text'-Klassen, wie Privat- oder Geschäftsbriefe, Unfallprotokolle, Sitzungsberichte, Vortragsmanuskripte usw. sind mir 'Genres'.

Dagegen läßt sich wiederum einwenden, daß etwa die 'Genres' Heldenlied, Märchen, Rätsel doch von meinem "Akt kreativer sprachlicher Autonomie eines menschlichen Individuums", 'Stil' genannt, nicht betroffen würden. Denn Heldenlied, Märchen, Rätsel sind doch angeblich Kollektiv-'Texte' mit 'Textsorten'-Charakter (s.u.). Daß das nicht stimmen kann, daß zu jedem Einzel-'Text' eines wie immer gearteten 'Genres' ein individueller Autor gehört, weil es kein 'schöpferisches Kollektiv' gibt, habe ich eben bei meiner Diskussion von National-, Zeit-, Epochen-, Gattungsstil gezeigt. Hinzu kommt das empirische Faktum, daß gerade wegen der potentiell $\mathrm{x}$-beliebigen Anzahl individueller, stilistisch aktiver 'Genre'-Autoren bei den drei genannten 'Text'-Klassen zahlreiche Einzeltext-Varianten überliefert sind, obwohl das überwiegende Gros, d.h. eine Unzahl von Einzeltext-Varianten, durch ihre transitorische vorschriftliche Oralität, durch ihr prätextuales 'Vor-Leben' als 'Rede', für unsere Schriftkultur verloren gegangen ist.

Diese Beobachtungen zu den Einzel-'Texten' von 'Genres' verweisen auf ein weiteres phänomenologisches Faktum: Den 'Text per se' gibt es nur als sprachphilosophisch-induktive Kategorie. Deshalb konnte Hjelmslev 'Text' definieren als "alle faktischen und möglichen Äußerungen einer Sprache". 'Text' muß sich zwangsläufig, synchron mit seiner durch den 'Stil' bewirkten Genesis, zu einem phänomenologischen Einzeltext-Bestandteil seines 'Genres' realisieren. Das heißt, auch jedes 'Genre' ist eine konzeptionelle Kategorie im Sinne Kants, eine Hypothese. Die 'Genre'-Kategorie ist aber doch eine 'naheliegende', direkte Komposition, ein Konzentrat aus dem 'Stil' ihrer Einzel-'Texte'. Indem ein Rätsel aufgeschrieben wird, aus 'Rede' zum 'Text' wird, objektiviert sich ein seinem 'Genre' über den 'Stil' zugeordneter Einzel-'Text' dieses Rätsels. Doch das Rätsel selbst - als geistig-thematische Konzeption, als sprachliche Konkretisierung einer Jolles'schen 'Geistesbeschäftigung'- ist zurückgetreten in die geistige Abstraktion der 'Sprache'. Von dort, aus der 'Sprache', kann es wieder objektiviert werden über den 'Stil' eines kreativ-aktiven Individuums. 'Genres' sind mithin durch spezifische inhaltliche, thematische und formal-strukturale Gegebenheiten ausgezeichnete, historisch determinierte 'Text'-Klassen, die sich unter poetologisch-ästhetischen Kriterien zu den drei "Naturformen" bzw. Grundgattungen der Literatur zusammendenken 
lassen - sofern sie unter poetologisch-ästhetische Kriterien fallen und nicht zu den pragmatischen 'Text'-Klassen bzw. pragmatischen 'Genres' gehören. Das heißt, in meiner Nomenklatur bedeutet das Wort 'Gattung' nur und ausschließlich eine der drei hypothetischen "Naturformen" oder Grundgattungen der poetologischen Literaturtheorie. Es wird von mir nicht - wie in der Poetik und sonst allgemein üblich - als Synonym für 'Genre' benutzt. Denn der Begriff 'Genre' steht mir für jede durch distinguierte 'Stil'Gleichheiten bzw. 'Stil'-Analogien verwandte Gruppe von Einzel-'Texten', ganz gleich, ob sie aus dem kommunikativ-pragmatischen, theoretisch-spekulativen oder ästhetisch-literarischen 'Text'-Bereich oder einer Überlagerung dieser 'Text'-Bereiche kommen.

Die 'Textsorten'-Klassifikationen und 'Textsorten'-Definitionen der Textlinguistik präsentieren sich entweder als Gordischer Knoten ${ }^{29}$ oder als definitorische Resignation, ${ }^{30}$ was zum größten Teil auf dem eingangs erwähnten und selektiv vorgeführten Dilemma konkurrierender 'Text'-Definitionen beruht. Ich kann mir, weil dadurch für meine eigene Definition nichts gewonnen wäre, eine Diskussion ersparen. Festzuhalten ist, daß der Terminus 'Textsorte' - wie der 'Text'-Begriff - ohne distinktive Eingrenzung ist und daß er - zwischen 'Text' und 'Rede' stehend - alles bedeuten kann, was ich eben als kommunikativ-pragmatische, theoretisch-spekulative oder ästhetisch-literarische 'Genres' bezeichnet habe. In meinem System, in dem aus der 'Sprache' durch 'Stil' entweder stilistisch Geformtes als 'Rede' transitorisch objektiviert wird oder aus der 'Sprache' durch 'Stil' sich 'Genres' als Klassen der 'Text'-Kategorie und als direkte stilistische Kompositionen von Einzel-'Texten' schriftlich-atransitorisch objektivieren, bezeichnet 'Textsorte' antistilistisch determinierte, stereotyp-formelhafte EinzeltextKomponenten, die aus Einzellexemen, subsyntaktischen Wortverbindungen, Einzelsätzen, asyntaktischen oder hypersyntaktischen Einheiten bestehen können. Anders, kürzer formuliert: 'Textsorten' sind gekennzeichnet durch die Abwesenheit eines stilistischen Aktes, im Sinne meiner Definition. Man könnte 'Textsorten' phylogenetisch einteilen in zwei Kategorien: 1. in eine historisch-metaphorische, im Schillerschen Sinne 'naive' Kategorie; 2. in eine ahistorisch-abstrakte, im Schillerschen Sinne 'sentimentalische' Kategorie. Zu den 'Textsorten' zähle ich alle sondersprachlichen und fachsprachlichen Cliché-Formulierungen; alle allgemeinen Gemeinplätze und Platitüden in

Ich verweise exemplarisch auf den Typologisierungsversuch von Interview, Brief, Telefongespräch, Arztrezept, Kochrezept, Inserat, Vorlesung etc. durch B. Sandig: Zur Differenzierung gebrauchssprachlicher Textsorten im Deutschen. In: E. Gülich/W. Raible (Hgg.), Textsorten: Differenzierungskriterien aus linguistischer Sicht. Frankfurt/M. 1972, S. 113-24 sowie auf den Artikel "Textsorte" in: Metzler-Lexikon-Sprache. Hg. von H. Glück. Stuttgart/Weimar 1993,S. 638 (mit Bibliographie).

30 K. Ermert meint in seinem Aufsatz "Briefsorten: Untersuchungen zu Theorie und Empirie der Textklassifikation". In: German. Ling. 20 (Tübingen 1979), S. 50: "Eine Textsorte... ist formal als eine Klasse oder Menge von virtuellen Texten zu bestimmen, die eine oder mehrere gemeinsame Eigenschaften haben." - S. 66: "Eine Textsorte kann allgemein als eine Klasse von Texten beschrieben werden, die einem komplexen Muster sprachlicher Handlungen zuzuordnen sind." 
Einzel-'Texten'; alle von Ernst Robert Curtius als 'Topoi', ${ }^{31}$ d.h. als feste clichéhafte Denk- und Aussageschemata, definierten vorgefertigten Formeln, Phrasen, Zitate, Wendungen, alle tradierten stereotypen Motive, Bilder, Embleme, einschließlich 'locus amoenus' und 'captatio benevolentiae'; alle Phraseologismen und Sprichwörter in Einzel-'Texten' usw. usw. Das Paradoxe dabei ist, daß eigentlich all diese antistilistischstereotypen Versatzstücke in Einzel-'Texten' ursprünglich konstituierende Bestandteile des individuell-autonomen 'Stils' gewesen sind, während nunmehr lediglich die Art und Weise ihrer - plagiatorischen - Benutzung in Einzel-'Texten' einen sekundären Bezug zum absoluten 'Stil'-Begriff herstellt. Das heißt, daß 'Textsorten' entstanden sind, und entstehen, als durchaus einmalige, aktiv-autonome 'Stil'-Leistung eines Individuums, das zumeist in die Anonymität zurückgetreten ist und seine 'Stil'-Leistung der 'Sprache per se' als Allmende zum allgemeinen Gebrauch übereignet hat. Solange man die Begriffe 'Textsorte' (zu lat. "sors, sortis"= das Gegebene, Geschickte, Anteilige) und 'Genre' nicht über multiplexe, konkurrierende Definitionsansätze vermischt und verunsichert, sehe ich keine eigentliche definitorische 'Textsorten'-Problematik. Schwieriger sind dagegen oft eindeutige 'Genre'-Definitionen. Auch dieses Dilemma scheint mir jedoch in der Regel lösbar, wenn man auf phänomenologisch-deskriptiver Basis, d.h. unter bewußter Zurückweisung aller spekulativen Versuchungen, logisch-distinktive sowie sozialhistorisch und kulturgeschichtlich fundierte Typologien und Terminologien entwickelt. Ich habe das seinerzeit für die Strickerschen Einzel-'Texte' des mittelhochdeutschen 'Genre' bîspel getan, angeregt durch die Tatsache, daß dieses 'Genre' auch als Exempel, Fabel, Fablel, Schwank, Significatio-Erzählung bezeichnet wurde und wird. Es hat sich dabei ergeben, daß der Einzel-'Text' bîspel zwar den 'Genres' Exempel, Fabel, Spruch verwandt ist, aber phänomenologisch deutlich eigene sprachlichstilistische und thematisch-formale Strukturen zeigt, die ein 'Genre' sui generis konstituieren, für das man am besten - unter sozialhistorischen Aspekten - den kulturhistorisch sinnvollen mhd. Terminus 'bîspel' beibehält, wobei "bî-" (wie das ags. "bî und das moderne engl. "by") eine instrumentale Funktion signalisiert, das 'bîspel' also ein 'Genre' ist, durch das eine didaktisch-thematische Intention besonders akzentuiert wird. ${ }^{32}$

Nachzutragen habe ich noch eine genauere Definition dessen, was ich mehrfach als 'Rede' angesprochen habe. Wie die 'Text'-Kategorie objektiviert sich mir die 'Rede'-Kategorie über und durch meinen 'Stil'-Begriff, wobei das 'verstandene Wissen' um 'Textsorten' noch wichtiger ist als für den schriftlichen, mithin korrigierbaren 'Text'. Es ist sogar zu fragen, wieweit sich 'Stil' heutzutage - über 2050 Jahre nach Marcus Tullius Cicero - in der freien, d.h. 'Text'-unabhängigen 'Rede' des Menschen noch objektivieren kann. Daß 'Stil' eine besondere Affinität zum 'Text' besitzt, läßt sich dagegen z.B. belegen durch die sieben erhaltenen 'Stil'-Versionen, denen Conrad Ferdi-

31 Europäische Literatur und lateinisches Mittelalter. 6 Bern/München (Francke) 1967.

32 Vgl.: "Einfache Formen beim Stricker". In: Werk-Typ-Situation. Stuttgart (Metzler) 1969, S. 118128. 
nand Meyer sein Gedicht "Der Brunnen/Der schöne Brunnen/Der römische Brunnen" unterwarf (vgl.: Sämtliche Werke. München/Zürich o.J.).

Als Analogon zu meiner 'Text'-Kategorie ergibt sich also eine ebenso theoretischideale und übergreifende 'Rede'-Kategorie, die über 'Rede'-Klassen und die den 'Rede'-Klassen stilistisch zugeordneten gesprochenen Einzel-'Reden' zum aktualisierten 'Sprach'-Phänomen wird. Attributiv ordne ich den aktualisierten Einzel-'Reden' das Adjektiv 'lingual' zu. Die Einzel-'Rede' existierte und existiert als transitorische Einheit vor und außerhalb der 'textualen' Schriftkultur. Sie hat jedoch seit dem Entstehen volkssprachlicher Schriftkulturen (auf dem Gebiete des heutigen Deutschland in Ansätzen seit der Karolingischen Renaissance) das Bestreben, aus dem transitorisch-lingualen Bereich in den permanent-textualen Bereich der Schriftkultur überzutreten, wodurch sie ihren speziellen 'naiven' Charakter sui generis, im Sinne Schillers, verliert. Jede aufgeschriebene Einzel-'Rede' wird kausaliter zum Einzel-'Text'. In den europäischen und nordamerikanischen Schriftkulturen des Medien-Verbundes existiert folglich nurmehr der pleonastische Zwitter einer 'Text'-'Rede'. Auf das ursprüngliche, sehr enge Verhältnis zwischen 'Sprache' und 'Rede' verweist das mittelhochdeutsche Wort "rede", das - noch nicht Lexem, sondern Idiom - bedeutete: Sprache; Vernunft, Verstand; Rede, Gespräch, Erzählung, Widerrede, Ausrede; Rechenschaft, Verantwortung; Verabredung, Versprechen, Abkommen, Vertrag; Text eines gesungenen Gedichtes; Thema des Gesprochenen, Sache; Handlung; Nachrede, Kunde, Nachricht. In dieser Semasiologie von "rede" ist eine 'Sprache'-'Rede'-Beziehung ausgedrückt, die Walther von Wartburg so formulierte: "Nur durch das Medium der Rede können wir ihr (der 'Sprache') näherkommen. Sie tritt immer nur in Teilstücken in Erscheinung. Es ist gewissermaßen so, daß das Gesamte der Sprache dauernd in Dunkel gehüllt ist, daß aber jeweils der Teil von ihr konkret wird, der durch den Lichtkegel der Rede herausgehoben wird. " ${ }^{33}$

Was ich unter 'Textsorte' als Einzellexem verstehe, läßt sich aus jedem Einzel'Text' des kommunikativ-pragmatischen 'Genres' "Zeitungsartikel" entnehmen. Aus einem "ZEIT"-Artikel vom 30.9.94 ${ }^{34}$ zitiere ich als Beispiel die folgenden 'Textsorten'Lexeme, die den Text als importierte Fremdwörter-Clichés durchsetzen: "Billboard, Talkmaster, Showkarten, Gagschreiber, Entertainer, zappen, Talentpool, Superstar, Babyboomer-Hipness, Bandleader, Sunnyboy". Eine noch dichtere 'Textsorten'-Besetzung mit Einzellexemen findet sich in den vom "ghostwriter" vorgestanzten Einzel'Text'-'Reden' der sogenannten (wieder ein 'Textsorten'-Lexem) "Talkshow", weil das Lexikon dieser Produkte so weit minimalisiert ist, daß etwa das über das Amerikanische entlehnte, ursprünglich lateinische 'Textsorten'-Lexem "super" (präfigiert, adjektivischadverbial und nominal gebraucht) als polysemantisches Universal-Cliché für alle virtuellen positiven Superlativ-Referenzen auftritt, wobei - analog zum Amerikanischen -

Einführung in die Problematik und Methodik der Sprachwissenschaft. 2 Tübingen 1962, S. 196, Anm. 1.

"Die Zunge in der Zahnlücke". In: Die Zeit 40 (30. 9. 94), S. 90. 
gegenüber dem Lateinischen eine willkürliche Wortklassen-Negierung stattgefunden hat.

Das Cliché-Einzellexem ist als 'Textsorte' in der Regel ahistorisch-abstrakt. Dazu gehören auch alle fach- und sondersprachlichen 'Kunstwörter' (wie: Akrostichon, illokutionär, Paralinguistik, Kardiolyse, Leukotomie), die einen betont theoretischfachidiomatischen Charakter besitzen.

Subsyntaktische 'Textsorten' sind mir alle - grundsätzlich historisch-metaphorischen - Phraseologismen, idiomatischen Wendungen, Redensarten, Redewendungen etc., alles, was seit 1993 35000-fach belegt als "Deutsche Idiomatik" erfaßt ist ${ }^{35}$ und was eine syntaktisch-thematische Einbindung benötigt, um referentiale Valenz zu gewinnen. Ich wähle eine exemplarische Redewendung, deren kulturgeschichtliche Etymologie noch unbekannt ist ${ }^{36}$ und deren Kontext aus einem Einzel-'Text' des 'Genres' "Zeitungsartikel" stammt: Bis zum Ende dieses Jahrhunderts werden die neuen Länder bei den alten "tief in der Kreide stehen".

Warum Textproduzenten auf die Idiomatik der 'Textsorte' zurückgreifen statt zu schreiben: "bei jemandem hoch verschuldet sein; jemandem großen Dank schulden", hat mit stilistisch-thematischen Intentionen zu tun: Die 'Textsorten'-Phrase "bei jemandem tief in der Kreide stehen" verfügt über eine bildhaft-sinnliche Valenz, die durch die Metaphorik der Phrase etabliert wird und die dem sonst banal-langweiligen Einzel'Text' des 'Genres' "Zeitungsartikel" eine aufhellende Farbigkeit, eine Verlebendigung verleiht; und zwar gerade dadurch, daß der unbekannte oder zu mindest obskure semasiologische Kern der Phrase nicht mehr kognitiv begriffen, sondern nunmehr intuitiv über die adverbial emphatisierte Metapher empfunden wird, daß nämlich eine Person metonymisch für eine Schuldsumme "in der Kreide steht" neben einer anderen Person. Durch die unbekannt-obskure Etymologie der 'Textsorten'-Wendung, die vor Jahrhunderten stilistisch-bewußt und individuell-autonom fixiert wurde, ist in der Phrase eine latent-immanente Bildlichkeit chiffriert, auf die der naive 'Text'-Rezipient mit unbewußter Neugier und Spannung reagiert; die Redewendung stimuliert sein Interesse, das der Kontext längst verspielt hatte.

Um zu demonstrieren, welche Chiffrierungen innerhalb des paradox 'offengeschlossenen' Systems 'Sprache' möglich sind, referiere ich verkürzt die sozialhistorischen und kulturgeschichtlichen Koordinaten der zitierten Redewendung: Beim Besuch der zahlreichen, gut erhaltenen mittelalterlichen Burgen im Fränkischen kann man Räume finden, die noch immer mit spätmittelalterlichem Mobiliar ausgestattet sind. Zu derartigen Räumen gehört auch das Schlafzimmer des einstigen Burgherren

35 H. Schemann, Deutsche Idiomatik: Die deutschen Redewendungen im Kontext. Stuttgart/Dresden (Klett) 1993.

36 Zu diesem Phraseologismus (und anderen) vgl. meinen Aufsatz: "Kulturgeschichtliche Kommentare zu historisch bedingten idiomatischen Redewendungen im heutigen Medien-Deutsch". In: Beiträge zur germanistischen Pädagogik 1. Hradec Králové 1994, S. 74-91. 
auf Lauenstein, der ein sehr vermögender Herr gewesen sein muß. $\mathrm{Zu}$ den im verbotenen Schlafgemach der Burgherrschaft verwahrten Wertsachen gehörten auch die Unterlagen über verliehene Geldbeträge, d.h. dort befanden sich u.a. die Schuldkonten der Schuldner. Im frühen und hohen Mittelalter verbuchte der Gläubiger die Darlehen seiner Schuldner, indem er bestimmte, eigenartige Längskerben in ein Holzbrettchen schnitt, in das sogenannte "Kerbholz". Diese Kerbhölzer wurden dann durch Brechen oder Schneiden halbiert, Gläubiger und Schuldner bekam je eine identisch gekerbte Hälfte des Kerbholzes als hölzernen Beleg. Man hatte also "wenig auf dem Kerbholz" oder "viel auf dem Kerbholz". Bei Tilgung der Schuld durch den Schuldner oder sonstigen Zahlungsverhandlungen wurden die beiden Kerbholz-Hälften zur Verifizierung ihrer richtigen Übereinstimmung zusammengehalten; sie mußten zu einander passen; das Kerbholz wurde damit zum 'Schuld-Symbol', was es bis heute im Phraseologismus geblieben ist. - Von den Kerbhölzern ist nichts geblieben; sie wurden nach der Schuldentilgung verheizt. Zudem ging man im Spätmittelalter auf ein anderes, bequemeres Buchungssystem über: Man brachte an der Schlafzimmerwand mit Hilfe von Scharnieren drei oder vier etwa $30 \times 40 \mathrm{~cm}$ große schwarze Holztafeln an, auf die der Gläubiger die ausstehenden Schulden der einzelnen Schuldner mit Kreide "ankreidete", und zwar in römischen Ziffern. Dabei war es für den Schuldner wichtig, sich später durch betrügerische Verlängerung der beiden Striche der römischen Fünf (V), die zugleich das mittelalterliche Graphem für den Vokal "U" war, nach unten zu einer römischen Zehn (X)- "kein X für ein U vormachen" zu lassen. - Die Burgherren auf dem fränkischen Lauenstein waren, wie gesagt, vermögende, geradezu reiche Herren. Deshalb findet man noch heute an der Wand des burgherrlichen Schlafgemaches vier der besagten schwarzen Holztafeln an Scharnieren, wie aufschlagbare Buchseiten, angebracht. Und dieses vier Tafeln tiefe hölzerne Schuld-Hauptbuch hatte System: Auf Tafel I standen die Schuldner mit einstelligen Schuldbeträgen, auf Tafel II die mit zweistelligen Schulden, auf Tafel III die mit dreistelligen Schuldsummen, auf Tafel IV schließlich die Schuldner, die wirklich, auf dieser 'tiefen Tafel', "tief in der Kreide standen", nämlich mit einem vierstelligen Schuldbetrag.

Was der 'Textsorte' Phraseologismus fehlt, ist eine didaktische Intention; sie ist insofern nicht kognitiv, als sie keine allgemeine Erkenntnis enthält. Statt dessen bleibt sie in ausgesprochen 'naiver' Weise verbunden mit einer zwar historisch-bildhaft erfaßten, aber dennoch überzeitlichen, weil allgemein existentiellen Erfahrung des menschlichen Individuums. Phraseologismen sind also ursprünglich eindrucksvolle individuellautonome 'Stil'-Leistungen, deren kulturgeschichtlich fixierte stilistische Brillanz seit Jahrhunderten von ihren Benutzern als 'Textsorte' plagiatorisch ausgenutzt worden ist. Im Falle des "Tief-in-der-Kreide-Stehen" ist es die metaphorisch kodifizierte Erfahrung der Schuld und der Schuldigkeit; bei der Wendung "auf den Hund kommen" die Erfahrung einer moralischen, materiellen oder existentiellen Not und Hoffnungslosigkeit; "einen Korb bekommen/erhalten" belegt die Erfahrung der Zurückweisung usw. Wegen dieser, einen allgemein-menschlichen Erfahrungs-Aspekt der conditio humana abbil- 
denden und vergegenwärtigenden Metaphorik sind Phraseologismen als 'Textsorte' oft international und übertragbar.

Die als autonomer Einzelsatz, als abgeschlossene syntaktische Einheit realisierte und benutzte 'Textsorte' der Sprüche, Sprüchwörter, Sprichwörter, Proverbien, Sentenzen, Geflügelten Worte etc. ist nicht minder zahlreich als die Mitglieder der subsyntaktischen 'Textsorte'. Im Gegensatz zu den metaphorisch-bildhaften, existentielle Erfahrungen kodifizierenden Phraseologismen belegt die 'Textsorte' Sprichwort eine kognitive, streng-didaktisch verarbeitete existentielle Erkenntnis des menschlichen Individuums. Auch das Sprichwort ist eine ursprünglich individuell-autonome 'Stil'-Leistung, die alle virtuellen Lebens-Erkenntnisse des Menschen, zusammen mit einer historischen Dimension, ein für alle Mal fixiert hat. Doch diese historische Dimension ist - im Gegensatz zum Phraseologismus - nicht auf metaphorische Weise kulturgeschichtlich evident, sie ist latent, in den Hintergrund getreten, oft verschwunden. Das heißt, das Sprichwort besitzt im Normalfall weder eine metaphorische Signifikanz noch einen evidenten historischen Bezug. Auch im 'Stil' unterscheiden sich die 'Textsorten' Phraseologismus und Sprichwort. Während der Phraseologismus durch komplexe, textimmanente, weil metaphorische Bildlichkeit sinnlich beeindruckt und erst dadurch zum apperzeptiven Nachdenken über kodifizierte Erfahrungs-Inhalte stimuliert, ist das Sprichwort von einer prägnant-durchsichtigen, prosaisch-schlichten, durch Autosemantika determinierten Stilistik, die - weil ursprünglich innerhalb einer 'Redesorte' realisiert - mnemotechnische Bindungen mittels Rhythmik, Alliteration und Reim einsetzt. Zum Spruch oder Sprichwort wird, mit betont didaktischer Intention und in leicht faßbarer, prägnanter Kürze stilistisch geformt, was eine von jedem einsehbare existentielle Erkenntnis, eine Weisheit oder eine moralische Lehre enthält. Die meist nötige apperzeptive Eigenleistung des wiederum plagiatorischen Benutzers und die apperzeptive Eigenleistung des Rezipienten eines derartigen Spruches oder Sprichwortes liegt darin, daß die auf einer stets banal-alltäglichen propositionalen Basis aufbauende didaktischintentionale Erkenntnis-Aussage eines historischen Sprichwortes erst durch die in Benutzer und Rezipienten kognitiv zu realisierende thematische Transparenz konstituiert wird; wobei ich das Attribut "historisch" als "vorindustriell" verstehe. Das Sprichwort "Die Katze läßt das Mausen nicht" z.B. ist eine banale, historisch allgemein gültige (in der Postmoderne allerdings durch Katzenfutter widerlegbare) AlltagsErkenntnis aus dem Bäuerlichen. Erst die zu realisierende thematische Transparenz stellt den Bezug zum Menschlichen her über die ahistorische sprichwörtliche ClichéErkenntnis: "Der Mensch ist ein Gewohnheitstier." und evtl. zugleich über ein tiefenpsychologisches Wissen um die instinktiven archetypischen Normen menschlichen Verhaltens. Unter diesem Aspekt sind historisch determinierte Sprüche und Sprichwörter 'syntaktische Symbole'. Ich betone dabei den Unterschied zwischen historischen und ahistorischen Sprichwörtern. Denn "Der Mensch ist ein Gewohnheitstier." ist zwar Sprichwort, oder besser: Sentenz-Cliché, aber diesem Satz-Cliché fehlt, mit der historischen Dimension, die thematische Transparenz; es ist eine in sich abgeschlossene 
Banalität des ausgehenden 19.Jahrhunderts, auf der Milieutheorie Hippolyte Taines und dem Determinismus Émile Zolas beruhend.

Die syntaktische 'Textsorte' ist im eigentlichen Sinne eine 'prosaische' (zu lat. "prosus"= gerade, schlicht). Und da sich im Sprichwort ein virtuelles Gesamtwissen für 'prosaische Gemüter' als 'Redesorte' und dann (seit dem späten 13.Jahrhundert) auch als 'Textsorte'- objektivierte, ist es nicht überraschend, daß der gelehrte Stadtsyndikus und Magister Johannes von Tepl im Jahre 1400 in seinem "Ackermann aus Böhmen" seine didaktische Gelehrsamkeit in ganzen Sentenzen-Katalogen zur Schau stellt; das gleiche Verfahren wendet die "Historia von D. Johann Fausten" 1587 an. ${ }^{37}$ Ich zitiere aus dem Anfang des 20.Kapitels des "Ackermannes": "DER TOT. Mit guter rede werden gesenftet die leute; bescheidenheit behelt die leute bei gemache; gedult bringet die leute zu eren; zorniger man kan den man nicht entscheiden...Anfanges geswistreit (Bruder) ist das ende. Wer ausgesant wirt, der ist pflichtig wider zu kumen. Was ie geschehen sol, des sol sich niemant widern (widersetzen). Was alle leute leiden mussen, das sol einer nicht widersprechen..." etc. Dieses Zitat belegt zum einen, daß sich Sentenz und Sprichwort, obwohl formal der gleichen 'Textsorte' zuzurechnen, thematisch unterscheiden: Der Sentenz fehlen grundsätzlich historische Dimension und thematische Transparenz des historisch determinierten Sprichwortes.

Zum anderen belegt das Zitat, was ich unter hypersyntaktischen 'Textsorten' verstehe. Sentenzen-Kataloge (wie bei Johannes von Tepl) und Sprichwörter-Sequenzen, die (wie im "Faustbuch") mit Sentenzen vermischt sein können, gehören ebenso dazu wie Geburts-, Heirats- und Todesanzeigen, Urkunden und Diplome, der 'locus amoenus', die 'captatio benevolentiae', Briefanfänge und Briefschlüsse, Mustersammlungen von Brief-Sorten und Predigten; Sitzungs-, Gerichts- und Unfallprotokolle; Kochrezepte und Bedienungsanleitungen; der Märchenanfang und der Märchenschluß (sofern das dafür benutzte 'Textsorten'-Cliché aus mehr als einem Satz besteht) sowie alle sonstigen hypersyntaktischen Schemata, die als Rahmen-Clichés benutzbar sind, und dgl. mehr, etwa die Roman-Clichés bzw. die Cliché-Romane der "Gartenlaube", besonders der Hedwig Courths-Mahler.

Die 'Textsorte' wird asyntaktisch, wenn zwar eine Häufung von vorgegebenen Clichés nach einem bestimmten Gliederungs- oder Struktur-Schema stattfindet, jedoch keine Syntaktik realisiert wird, also eine Form der Ellipse vorliegt, sofern Syntaktisches vom Rezipienten zu ergänzen ist. Als eindrucksvollste und umfänglichste asyntaktische 'Textsorte' fällt mir Franz Dornseiff, Der deutsche Wortschatz nach Sachgruppen (Berlin 1959,5 ) ein, wobei ich vor allem an die 20 Hauptabteilungen mit je 20-90 Begriffsnummern denke. Außerdem gehören dazu: alle Wörterbücher, Synonymen- und Reimlexika, Bibliographien, Literatur-Kalender, Gelehrten-Kalender, die asyntakti- 
schen Einleitungsparagraphen der Literatur-Lexika (z.B. KLL), schließlich alle Telephon- und Adreßbücher, Versandhauskataloge, Radio- und Fernsehprogramme etc.

Die 'Textsorte', gleich welcher Art, ist - wie gesagt - ein wichtiges und konstituierendes, potentiell stilistisch benutzbares Strukturelement jedes Einzeltextes, und sie ist -als 'Textsorte' - per se unabhängig von dem einem Einzeltext übergeordneten 'Genre'. Als Regel gilt, daß die 'Textsorten'-Frequenz mit dem pragmatisch-kommunikativen oder dem abstrakt-theoretischen Charakter eines Einzeltextes zunimmt. Anders ausgedrückt: Je größer die aktive 'Stil'-Kompetenz oder der individuell-autonome 'Stil'-Wille eines Einzeltext-Autors, desto geringer ist die 'Textsorten'-Frequenz seines Textes.

Ich belege diese Feststellung durch einen eigenen Einzeltext, den ich als Anhang bringe. Der Text ist entstanden, als ich beabsichtigte, für eine stilistische Übung die Symbol-Dimensionen von "Hand" zu demonstrieren. Weder wollte ich mit diesem Text eine 'Stil'-Kompetenz unter Beweis stellen noch beherrschte mich irgendein 'Stil'Wille. Ich notierte mir also zu dem Phraseologismus "mit leeren Händen" - der mir aus Schillers "Wallenstein" einfiel - eine volle Seite mir konnotativ einfallender HandPhraseologismen. Und da es sich bei der 'Stil'-Übung um die stilistische Interpretation eines Liebesgedichtes handelte, fielen mir - wieder analog-assoziativ zu der subsyntaktischen 'Textsorte' Phraseologismus - zwei oder drei passende hypersyntaktische 'Textsorten' als Rahmen-Clichés ein. Wie bei 'Textsorten' üblich, schrieb sich dieser Einzeltext 'von selbst'. Am Ende waren noch genügend Hand-Phraseologismen für einen zweiten 'Textsorten'-Text übrig. ${ }^{38}$

Schwierig war die Frage meiner Studenten zu beantworten, zu welchem - ja schließlich stilistisch determinierten - 'Genre' denn dieser Einzeltext zu rechnen sei. Denn 'Stil' hatte bei der Produktion des Textes per definitionem direkt nicht stattgefunden. Die einzige 'Stil'-Leistung war eine höchst indirekt-sekundäre, eine eigentlich über die benutzten 'Textsorten' heteronom gesteuerte, plagiatorisch 'sich von selbstereignende': Ich hatte innerhalb der Rahmen-Clichés 'Erfolgsbiographie', 'Kalendergeschichte', 'Liebesgeschichte' idiomatische Clichés in didaktisch-logischer Absicht arrangiert. Folglich läßt sich dieser Einzeltext auch keinem der drei genannten 'Genres' zuordnen. Es ist vielmehr - phänomenologisch betrachtend - ein pädagogisch-didaktisches Exemplum, in dem die übliche dogmatisch-moralische Exemplum-Lehre durch eine pädagogisch-didaktische ersetzt worden ist.

Je größer die aktiv-kreative 'Stil'-Kompetenz oder der individuell-autonome 'Stil'Wille eines Einzeltext-Autors, desto geringer ist die 'Textsorten'-Frequenz eines Textes: Daraus müßte man nach dem 'logos' der Sprache folgern, daß es zu dem 'MinimalStil' bzw. dem 'Negativ-Stil' meines Textes als Antithesis den 'Puren Stil' als Einzeltext zu geben hat und daß dieser 'Pure Stil' in einem literarisch-ästhetischen Einzeltext zu 
suchen ist. Mir fallen dazu eine Reihe von Beispielen 'Puren Stils' ein. Ich nenne nur drei allgemein bekannte: den Prolog Gottfrieds von Straßburg zum "Tristan"; den Prolog Wolframs von Eschenbach zum "Parzival"; Rainer Maria Rilkes Epitaph-Inschrift.

Da die beiden ersten Beispiele wegen ihrer - als und im 'Stil' ihrer Autoren realisierten - komplexen mittelhochdeutschen Semasiologie, wegen ihrer - um mit Gottfried zu sprechen - 'kristallinen' Durchsichtigkeit, ihrer polyvalenten Referentialität und wegen ihrer kulturhistorisch etablierten eigenwilligen Bildhaftigkeit eigentlich nicht angemessen ins Neuhochdeutsche übersetzbar sind, ${ }^{39}$ möchte ich an Rilkes kurzem Text demonstrieren, was man unter textsortenfreiem 'Purem Stil' verstehen kann.

"Rose, oh reiner Widerspruch, Lust,

Niemandes Schlaf zu sein unter soviel

Lidern." 40

Rilkes Text besteht aus einem einzigen, in seiner Prädikation durch das Fehlen der finiten Verbalform "ist" elliptischen, und damit emotional verdichteten Satz. "Niemandes Schlaf zu sein unter soviel Lidern" ist "reiner Widerspruch", ist "Lust" und ist letzten Endes "Rose". Doch das wäre als 'Stil' für Rilke nicht 'pur' genug. Denn es würde ja eine 'normalisierte', damit clichéhafte Syntaktik etablieren; und das durch seine enorme Frequenz clichéhaft-farblose finite Kopula-Ist würde - als im Deutschen am häufigsten gebrauchtes verbales Lexem - das Ästhetisch-Esoterische des Textes

39 Für Wolframs "Parzival"-Prolog habe ich den Versuch einer angemessenen nhd. Übersetzung unternommen: Sind Herz und Inteliekt eines Menschen erfüllt von kritisch suchender religiöser und ethischer Unruhe, dann ist die Seele dieses Menschen notwendigerweise geistigen Wehen und schmerzhaften Zweifeln unterworfen, ist die Seele doch das Organ unseres religiösen und ethischen Bewußtseins. Wenn also eines Menschen geistige Fundamente durch die eben genannten inneren Turbulenzen erschüttert werden, dann gleicht seine Seele symbolisch dem weißen und schwarzen Gefieder der Elster. Denn seine verunsicherte, gleichsam 'flatternde' Seele kann sich - aufgrund des menschlichen freien Willens - entweder richtig (d. h. 'weiß') oder falsch (d. h. 'schwarz') entscheiden. Die 'weiße' Entscheidung führt zu Lob und Preis, Ehre und Erlösung; die 'schwarze' Entscheidung bedeutet Schande und Verdammnis. Doch gerade wegen dieser symbolischen Schwarz-Weiß-Fakultäten der menschlichen Seele, gerade weil sowohl Himmel als auch Hölle um die Vorherrschaft in der Seele streiten, hat der Mensch allen Grund, optimistisch und zuversichtlich zu sein, weil er aus freiem Willen die richtige Entscheidung fällen kann und wird, die ihn erlöst. Der entscheidende geistige Faktor in diesem Entscheidungs-Prozeß ist jedoch eines Menschen intellektuelle Tugend unbedingter Treue zu sich selbst. Denn sie ist die notwendige Grundlage seines beständigen, unbeirrbaren Strebens nach dem Guten, Richtigen. Besitzt ein Mensch jedoch diesen entscheiden geistigen Faktor nicht, suchen ihn statt dessen Wankelmut und Unbeständigkeit heim, dann wird die Schwärze religiösen und ethischen Versagens den Sieg gewinnen; und der Mensch wird in der Hölle enden, d. h. in seelisch-geistiger Verzweiflung, Umnachtung und sozialer Misere.

40 R. M. Rilke, Werke in drei Bänden. Bd. II. Frankfurt(M)/Leipzig (Insel) 1991, S. 185 - Die von vielen Interpreten bemühte Homophon-Identifikation von "Liedern" gibt interpretatorisch nichts her, sie widerspricht geradezu (s. u.) dem metaphorischen 'logos' Rilkes in diesem Text. 
kontaminieren. Folglich hat der Stilist des Textes die zu erwartende 'normale' grammatische Prädikation in eine logisch-durchsichtige metaphorisiert und sie textimmanentinfinit - d.h. in einer umfassenden, wenn man so will 'globalen' Funktion - untergebracht in dem Verbum essendi "zu sein" der komplexen Subjekt-Gruppe seines Satzes. ${ }^{41}$

Im einzelnen beginnt der Text mit dem scheinbaren Subjekt "Rose", das sich aber bei der interpretatorischen Apperzeption als syntaktisches Paradoxon erweist, denn dieses Schein-Subjekt "Rose" ist realiter allegorisches Bild-Zentrum der Prädikation. Denn "Rose" ist Allegorie; sie bedeutet nicht, sondern sie ist ästhetisch erfaßtes Sinnbild des mit emphatischer Apostrophe ("oh") eingeführten, dann synästhetisch-metaphorisch realisierten "reinen Widerspruches", zu dem als Klimax und als zweite appositionelle Amplifikation der zweite allegorische Aspekt von "Rose" gefügt ist. "Rose" ist nicht nur "reiner Widerspruch", sie ist zugleich - als Steigerung der Synästhesie "reiner Widerspruch" - "Lust", d.h. nicht Neigung oder Verlangen, nicht Freude oder Wohlgefühl, sondern äußerste 'Be-Friedigung', eine metaphorisch "Unter-soviel-Lidern" 'tief' versinnbildlichte, 'ver-innerlichte' 'Be-Friedigung'. Damit nicht genug: Auch "Schlaf zu sein" ist eine, verbal finalisierte, Allegorie, indem der Schlaf durch das Verbum essendi zu einer Seinsform erhoben wird, die sich metaphorisch mit "Niemandes" verbindet. Wobei zu fragen ist, ob der Stilist mit "Niemand" auf "Nemo/Outis" verweisen wollte, auf den namenlos umhergetriebenen Odysseus als Präfiguration des namenlosen Viator mundi der christlichen Seinsexegese, d.h. auf den Menschen an sich, wodurch mystisch-paradox mit dem "Niemand" ein "Jedermann" gemeint wäre, besonders der "rühmende" Dichter als Viator mundi und Mensch an sich.

Rilkes ganzes Satz-Gebilde erweist sich so als expansive Metapher, d.h. als eine bildhaft-kristalline 'Stil'-Komposition, deren einzelne Motive zusammengefügt sind zu einem in sich stimmigen, harmonischen Ganzen und deren Sinnbildlichkeit eine maximalisierte, komplexe Imaginations-Referentialität aufweist. Das zeigt sich letzten Endes auch in der chiastischen, über die 'Stil'-Syntaktik objektivierten Bild-Struktur dieser Inschrift: Wie ich bereits sagte, ist "Niemandes Schlaf zu sein unter soviel Lidern" zugleich "reiner Widerspruch" und "Lust" und ist letzten Endes "Rose" - weil "Rose" Allegorie von "reiner Widerspruch" und Allegorie von "Lust" ist sowie Symbol von "Niemandes Schlaf...unter soviel Lidern". Aber "Rose" ist auch - chiastisch objektiviert - "Niemandes Schlaf..unter soviel Lidern", und sie ist - eben deshalb - ein emphatisch bewußter "reiner Widerspruch" und ist "Lust". Die äußerste, 'ver-innerlichte', deshalb metonymisch als "Lust" empfundene 'Be-Friedigung' - die allegorisch "Rose" ist, weil sich diese als Symbol der "sovielen Lider" 'offenbart' - wird einzig erreicht - so will es die stilistische Versinnbildlichung des Textes - in der "Lust" oder 'Be-Friedigung' durch den Schlaf, der ein Schlaf des "Niemandes" oder des 'Jedermanns' ist und der in

41 Das 'verbum essendi' in seiner 'infiniten' Form trägt in dieser Grabinschrift eine zusätzliche eschatologische Symbolik. 
diesem Epitaph-Text als euphemistisch-mythische Metonymie für den Tod steht. Denn Hypnos und Thanatos sind - wie Rilke wußte - seit je Brüder.

Auf diese Weise wird aus der Opposition, aus dem stilistisch-syntaktisch axial gesetzten "reinen Widerspruch" zwischen der "Lust" auf der einen Seite - die als tiefe 'Be-Friedigung'Schlaf, damit Tod bedeutet - und der "Rose" - die ja vor allem auch Liebe und Leben symbolisiert - auf der anderen Seite der Opposition, auf der anderen Seite des "reinen Widerspruchs" eine über die Paradoxa christlicher Mystik und Symbolik vollzogene Coincidentia oppositorum.

Ich bin mir bewußt, daß Typologie und Nomenklatur dieses Beitrages nicht mehr und nicht weniger sind, sein können, als 'stilistische Versuche', die - wie alle Stilistik, wenn ich mich nochmals auf Rilkes Epitaph beziehen darf - zum Nachdenken stimulieren möchten, besonders hinsichtlich unserer pädagogisch-didaktischen Aufgabe. Denn Textlinguistik hatte ursprünglich einen dezidiert pragmatischen Aspekt und sollte nicht - um nochmals 'Textsorte' zu benutzen - zum Glasperlenspiel im Elfenbeinturm werden.

\section{Anhang}

Peter konnte bereits mit jungen Jahren in allen Dingen eine glückliche Hand beweisen. Das verdankte er seinem Vater. Der hatte Peter zwar eine feste Hand spüren lassen, aber er hatte auch die vorzügliche Erziehung seines Sohnes von langer Hand vorbereitet und zum richtigen Zeitpunkt stets selbst in die Hand genommen. Und wenn immer möglich, ließ er dem Sohne bei persönlichen Entscheidungen freie Hand. So kam es, daß Vater und Sohn bereit waren, für einander die Hand ins Feuer zu legen. Peters Selbstvertrauen ging so weit, daß er glaubte, alles mit der linken Hand oder, wenn nötig, unter der Hand erledigen zu können. Peters Vater brauchte seine Hand folglich bald nicht mehr über seinen Sohn zu halten, vielmehr wurde der Sohn mit 21 des Vaters rechte Hand.

Doch eines Tages hatte sich Peter nicht mehr in der Hand. Das war, als er Petra begegnete, die eigentlich bereits in festen Händen war. Zuerst sagte sich Peter: "Es ist wohl besser, ich lasse die Hände davon, sonst geht es mit schließlich wie Werther, und ich lege Hand an mich." Aber das Mädchen ging ihm nicht aus dem Sinn, so daß es sogar sein Vater merkte, der meinte: "Hand aufs Herz, Peter, bist du verliebt?"

Peter beschloß, die Hände nicht länger in den Schoß zu legen, sondern sein Herz in beide Hände zu nehmen. Fühlte er doch, daß er es in der Hand hatte, um Petra zu werben. Und er hatte Erfolg.

Zum entscheidenden Besuch bei Petras Eltern kam Peter nicht mit leeren Händen, sondern mit Orchideen für die künftige Schwiegermutter, der er die Hand küßte. Dann drückte er Petras Vater die Hand. Nach dem Abendessen kam Peter zur Sache: "Petra 
hat versprochen, mir die Hand fürs Leben zu reichen. Wir beide wollen Hand in Hand durchs Leben gehen. Ich halte deshalb bei Ihnen um Petras Hand an und verspreche Ihnen zugleich in die Hand, daß Petra bei mir in guten Händen sein wird, ich werde sie geradezu auf Händen tragen." - "Gib mir die Hand darauf, Peter", sagte Petras Vater. Und die bewegte Mutter legte den Hände haltenden Verlobten die Hände auf, um ihnen Glück zu wünschen.

\section{Zusammenfassung}

Die multiplexen, miteinander konkurrierenden 'Text'-Definitionen der Textlinguistik und Texttheorie machen es unmöglich, mit ihnen wissenschaftlich oder pädagogisch zu arbeiten. Mein Beitrag zur Problematik von Texttypologien mußte deshalb am Grundphänomen 'Sprache' ansetzen und, ausgehend von den sprachphilosophischen Ideen Herders und Wilhelm von Humboldts sowie den sprachtheoretischen Überlegungen L.Hjellmslevs und H.-M.Gaugers, eine Konzeption von 'Sprache' als logische Basis für eine darauf aufbauende eigene, kohärent strukturierte Nomenklatur entwickeln, in der die sprachtypologischen Phänomena 'Stil', 'Text', 'Rede', 'Gattung'-'Genre' und 'Textsorte' definitorisch eingebunden sind. Dabei zeigt sich, daß das Phänomen 'Stil' für die übrigen sprachlichen Kategorien instrumentale Bedeutung besitzt. Alle typologischen Definitionen werden durch exemplarisch-empirische Argumente gestützt, so auch abschließend antithetisch - wegen ihrer besonderen Relevanz- 'Textsorten-Stil' (anhand eines eigenen Textes) und 'Purer Stil' (anhand R.M.Rilkes Epitaph).

\section{Povzetek}

\section{JEZIK, BESEDILO IN BESEDILNE VRSTE: O PROBLEMATIKI BESEDILNE TIPOLOGIJE}

$\mathrm{V}$ besediloslovju in besedilni teoriji obstaja več različnih, med seboj konkurenčnih definicij pojma "besedilo", zato jih v znanstveni in pedagoški praksi ni moč uporabiti.

Zato sem moral v svojem prispevku o problematiki tipov besedil pričeti z osnovnim pojmom "jezik", ki ga utemeljujem $z$ jezikovnofilozofskimi nazori Herderja in Wilhelma von Humboldta kot tudi z jezikovnoteoretičnimi razmišljanji L. Hjelmsleva in H.-M. Gaugerja. Poleg tega je bilo potrebno razviti lastno zasnovo pojma "jezik" kot logično podlago za koherentno strukturirano nomenklaturo, ki vključuje tudi jezikovnotipološke pojme "slog", "besedilo", "govor", "zvrst" - "žanr" in "besedilna vrsta". Pri tem se je pokazalo, da je pojem "slog" temeljnega pomena za druge jezikovne kategorije. Vse tipološke definicije sem utemeljil z zgledi, prav tako poslednji, nasprotujoči si, ključni definiciji "slog besedilne vrste" ( $\mathrm{z}$ lastnim besedilom) in pojem "čisti slog" (z "Epitaphom" R. M. Rilkeja). 